\title{
Intergenerational transmission of maltreatment and psychopathology: the role of antenatal depression
}

\author{
D. T. Plant ${ }^{1 *}$, E. D. Barker ${ }^{2}$, C. S. Waters ${ }^{3}$, S. Pawlby ${ }^{1}$ and C. M. Pariante ${ }^{1}$ \\ ${ }^{1}$ Department of Psychological Medicine, Institute of Psychiatry, King's College London, UK \\ ${ }^{2}$ Department of Psychological Sciences, Birkbeck, University of London, UK \\ ${ }^{3}$ School of Psychology, Cardiff University, UK
}

Background. Maternal experience of childhood maltreatment and maternal antenatal depression are both associated with offspring childhood maltreatment and offspring adjustment problems. We have investigated the relative impact of maternal childhood maltreatment and exposure to depression in utero on offspring maltreatment and psychopathology.

Method. The sample included 125 families from the South London Child Development Study. A prospective longitudinal design was used. Data on maternal childhood maltreatment, maternal antenatal depression (36 weeks of pregnancy), offspring childhood maltreatment (age 11 years) and offspring adolescent antisocial behaviour and depression (ages 11 and 16 years) were obtained from parents and offspring through clinical interview.

Results. Mothers who experienced childhood maltreatment were significantly more likely to be depressed during pregnancy [odds ratio (OR) 10.00]. Offspring of mothers who experienced only childhood maltreatment or only antenatal depression were no more at risk of being maltreated or having psychopathology; however, offspring of mothers who experienced both maternal childhood maltreatment and antenatal depression were exposed to significantly greater levels of childhood maltreatment and exhibited significantly higher levels of adolescent antisocial behaviour compared with offspring not so exposed. Furthermore, maternal childhood maltreatment accounted for a significant proportion of the variance in offspring childhood maltreatment in only those offspring exposed to depression in utero.

Conclusions. Maternal childhood maltreatment and maternal antenatal depression are highly associated. The cooccurrence of both insults significantly increases the risk of offspring adversity. The antenatal period is an optimum period to identify vulnerable women and to provide interventions.

Received 11 November 2011; Revised 2 May 2012; Accepted 17 May 2012; First published online 14 June 2012

Key words : Adolescents, antisocial behaviour, maltreatment, pregnancy, prenatal stress.

\section{Introduction}

It is widely recognized that many prenatal factors that influence offspring development do not occur by chance but are influenced by other, often unmeasured, maternal characteristics (Maughan et al. 2004; Thapar \& Rutter, 2009; Rice et al. 2010). Studies have revealed that exposure to maternal depression in utero increases the risk of exposure to childhood maltreatment (Pawlby et al. 2011), and also the risk of offspring psychopathology in later life (Seckl \& Holmes, 2007; Talge et al. 2007). Maternal experiences of childhood maltreatment are also associated with offspring exposure to maltreatment (Sidebotham \& Heron, 2006;

\footnotetext{
* Address for correspondence: D. T. Plant, 2-059 James Black Centre, Institute of Psychiatry, King's College London, 125 Coldharbour Lane, London SE5 9NU, UK.

(Email : dominic.plant@kcl.ac.uk)
}

Berlin et al. 2011) and offspring psychopathology (Collishaw et al. 2007; Miranda et al. 2011). To our knowledge, no study has examined simultaneously the effects of maternal childhood maltreatment and antenatal depression on offspring adverse outcomes, including both exposure to childhood maltreatment and psychopathology, as a putative mechanism underlying the intergenerational transmission of maltreatment and psychopathology.

Childhood maltreatment has intergenerational consequences. In a prospective American study of over 400 mother-child dyads, maternal history of physical abuse was found to predict offspring county court allegations and substantiations of maltreatment in the first 2 years of life (Berlin et al. 2011). In a British sample of several thousand families, maternal childhood maltreatment predicted investigations of offspring maltreatment by social services in early childhood (Sidebotham \& Heron, 2006), in addition to emotional 
and behavioural adjustment problems at 4 and 7 years (Collishaw et al. 2007). Moreover, a recent Spanish study has demonstrated maternal childhood maltreatment to predict offspring adolescent symptoms of disruptive behaviour disorders (DBDs; Miranda et al. 2011).

Experiences of childhood maltreatment have consistently been shown to be associated with an increased risk for adulthood depression (Bifulco et al. 2002; Edwards et al. 2003; Widom et al. 2007; Nanni et al. 2012). However, less is known about the relationship, in women, between childhood maltreatment and adulthood depression specifically in the antenatal period, which is the first step in this putative 'intergenerational' pathway. Findings from studies that have addressed this question suggest an association with depressive symptomatology during pregnancy (Romano et al. 2006; Chung et al. 2008; Rich-Edwards et al. 2011). However, to our knowledge, no study has examined the link between experiences of childhood maltreatment and the development of clinically diagnosed adulthood antenatal depression.

As mentioned earlier, one reason why depression is important in this context is that, when occurring in women during the antenatal period, it has the potential to influence offspring outcome at the levels of exposure to maltreatment (Pawlby et al. 2011) and later psychopathology, such as adolescent DBDs and depression (Pawlby et al. 2009; Hay et al. 2010). We have recently demonstrated the synergistic effects of exposure to maternal antenatal depression and exposure to childhood maltreatment on adolescent psychopathology (Pawlby et al. 2011). This interplay between multiple insults, where the conferred risks combine in non-additive ways, may be interpreted as reflecting the role of confounders to the initial association that have previously gone unrecognized (Rutter, 2006; Thapar \& Rutter, 2009). We sought to investigate whether maternal childhood maltreatment and maternal antenatal depression are indeed part of a single pathway of the intergenerational transmission of maltreatment and psychopathology. Thus, we tested three hypotheses:

(1) There is an association between maternal childhood maltreatment and offspring childhood maltreatment and offspring adolescent psychopathology.

(2) There is an association between maternal childhood maltreatment and maternal antenatal depression.

(3) Maternal antenatal depression influences the effect of maternal childhood maltreatment on offspring outcome.
Table 1. Characteristics of the sample at 16 years $(n=125)$

\begin{tabular}{|c|c|}
\hline \multicolumn{2}{|l|}{ Mother's age at birth (years) } \\
\hline Mean (S.D.) & $26.3(5.0)$ \\
\hline Range & $17-44$ \\
\hline \multicolumn{2}{|l|}{ Marital status in pregnancy (\%) } \\
\hline Married & 68 \\
\hline Cohabiting & 27 \\
\hline Single & 5 \\
\hline \multicolumn{2}{|l|}{ Social class ${ }^{\mathrm{a}}(\%)$} \\
\hline Working class & 90 \\
\hline \multicolumn{2}{|l|}{ Maternal education (\%) } \\
\hline Basic qualifications or higher & 74 \\
\hline \multicolumn{2}{|l|}{ Parent in household at age $16^{\mathrm{b}}(\%)$} \\
\hline Two biological parents & 52 \\
\hline Biological mother & 39 \\
\hline Biological father & 5 \\
\hline $\begin{array}{l}\text { No biological parent (other relative, } \\
\text { living independently, under supervision } \\
\text { of social services) }\end{array}$ & 4 \\
\hline \multicolumn{2}{|l|}{ Offspring's gender (\%) } \\
\hline Female & 54 \\
\hline \multicolumn{2}{|l|}{ Offspring's birth order (\%) } \\
\hline Firstborn & 48 \\
\hline \multicolumn{2}{|l|}{ Offspring's ethnicity ${ }^{\mathrm{c}}(\%)$} \\
\hline White British & 72 \\
\hline $\begin{array}{l}\text { Other (White non-British, African, Caribbean, } \\
\text { South Asian, East Asian, mixed) }\end{array}$ & 28 \\
\hline
\end{tabular}

\section{Method \\ Design}

The hypotheses were tested in the context of a prospective longitudinal study on the effects of maternal mental health on offspring development. Clinical interviews occurred at 36 weeks of pregnancy, 3 and 12 months postpartum, and at 4, 11 and 16 years.

\section{Sample}

The participants were 125 women, representing $82 \%$ of a random sample of 153 pregnant women who were recruited into a prospective longitudinal community study, the South London Child Development Study (Sharp et al. 1995). The characteristics of the women and their offspring at age 16 years are summarized in Table 1. The subsample of 125 women who provided information on their childhood maltreatment history did not differ statistically from the original random sample on any of the sociodemographic variables $(p>0.05)$. 


\section{Measures}

Additional details on the measures are described in the online supplement to this paper.

\section{Maternal childhood maltreatment}

We obtained mothers' retrospective reports of childhood experiences of physical abuse, sexual abuse, emotional neglect and physical neglect. Maltreatment was rated if two or more types of maltreatment were reported. This threshold has previously been identified as a valid index of childhood maltreatment (Danese et al. 2008).

\section{Maternal antenatal depression}

ICD-9 diagnoses of depression were made of the women's current mental state at 36 weeks of pregnancy using the Clinical Interview Schedule (CIS; Goldberg et al. 1970).

\section{Maternal depression from birth to 16 years}

We rated current and retrospective diagnoses of maternal depression made from psychiatric interviews in the first year postpartum (CIS) and at offspring ages 4, 11 and 16 years [Schedule for Affective Disorders and Schizophrenia-lifetime version (SADS-L) ; Endicott \& Spitzer, 1978]. A binary variable of whether depression had ever been experienced at some point between birth and 16 years was generated.

\section{Mother's own history of juvenile antisocial behaviour}

We obtained mothers' retrospective reports of their own conduct symptoms before age 16 .

\section{Mother's own history of psychiatric problems}

We rated retrospective diagnoses of psychiatric problems prior to the index pregnancy from psychiatric interviews at 4 years (SADS-L).

\section{Family stability}

We recorded whether the offspring lived with two biological parents at 16 years.

\section{Offspring childhood maltreatment}

We rated maltreatment from the combined (parent and child) 11-year Child and Adolescent Psychiatric Assessment (CAPA; Angold \& Costello, 2000) interview reports of the children's experiences of harsh discipline during the 3-month period immediately preceding the interview, along with information about any lifetime experiences of physical and sexual abuse.

\section{Offspring adolescent antisocial behaviour}

DSM-IV symptoms of DBDs were recorded from combined (parent and child) psychiatric interview reports at 11 and 16 using the CAPA. A latent variable of adolescent (11 and 16) antisocial behaviour was generated.

\section{Offspring adolescent depression}

DSM-IV symptoms of depression were recorded from combined (parent and child) CAPA interview reports at 11 and 16 years. A latent variable of adolescent (11 and 16) depression was generated.

\section{Additional sociodemographic variables}

We controlled for maternal age at the index pregnancy, maternal education, offspring ethnicity and offspring gender.

\section{Statistical analyses}

The analyses proceeded in five steps. In the first step we constructed latent variables of offspring adolescent antisocial behaviour and offspring adolescent depression through confirmatory factor analysis, with observed DSM-IV symptoms at ages 11 and 16 years serving as indicators for the factors. In the second step we conducted bivariate analyses. Third, we performed regression analyses to evaluate the relationship between maternal childhood maltreatment and maternal antenatal depression. Fourth, we evaluated the prevalence of offspring childhood maltreatment and offspring adolescent psychopathology as a function of mothers' cumulative stressful experiences. In the fifth step we estimated a single path analytic model for the pathway from maternal childhood maltreatment to offspring adolescent psychopathology, assessing the relative contributions of maternal antenatal depression and offspring childhood maltreatment.

Log transformations were applied to continuous variables to improve the normality of the distributions and permit parametric analyses. Bivariate analyses and regressions were conducted in SPSS version 17 (SPSS Inc., USA). We used Pearson's $r$ correlation to test for association between continuous variables, the point-biserial correlation to test for association between dichotomous and continuous variables, and the $\chi^{2}$ test to assess the relationship between nominal variables. ANOVA with Bonferroni correction was used for multiple comparisons. MPlus version 6.1 (Muthén \& Muthén, 1998-2010) was used to conduct the confirmatory factor analysis and path analysis. Full maximum likelihood estimation with robust 
Table 2. Correlations (Pearson's r) among 11-year and 16-year DSM-IV symptoms

\begin{tabular}{lllllll}
\hline & $(1)$ & $(2)$ & $(3)$ & $(4)$ & Mean (s.D.) & $n$ \\
\hline (1) 11-year DBD symptoms & - & & & $2.80(4.34)$ & 111 \\
(2) 11-year depression symptoms & $0.32^{* *}$ & - & & & $0.63(0.92)$ & 114 \\
(3) 16-year DBD symptoms & $0.40^{* *}$ & 0.15 & - & & $2.74(4.12)$ & 101 \\
(4) 16-year depression symptoms & $0.35^{* *}$ & $0.21^{*}$ & $0.19 \dagger$ & - & $1.24(1.28)$ & 106 \\
\hline
\end{tabular}

DBD, Disruptive behaviour disorder; S.D., standard deviation.

$\dagger p<0.10$ (trend), ${ }^{*} p<0.05,{ }^{* *} p<0.01$.

Table 3. Intercorrelations between study variables. $\kappa$ coefficients are reported for associations with nominal variables, point-biserial coefficients for associations with continuous and dichotomous variables, and Pearson's $r$ coefficients for associations with continuous variables

\begin{tabular}{|c|c|c|c|c|c|c|c|c|c|c|}
\hline & $(1)$ & $(2)$ & (3) & $(4)$ & (5) & $(6)$ & (7) & (8) & (9) & $n$ \\
\hline (1) Maternal childhood maltreatment & - & & & & & & & & & 125 \\
\hline (2) Maternal antenatal depression & $0.43^{* *}$ & - & & & & & & & & 125 \\
\hline (3) Offspring childhood maltreatment & $0.28^{* *}$ & $0.27^{* *}$ & - & & & & & & & 114 \\
\hline (4) Offspring adolescent antisocial behaviour & $0.31^{* *}$ & $0.28^{* *}$ & $0.37^{* *}$ & - & & & & & & 114 \\
\hline (5) Offspring adolescent depression & 0.00 & 0.06 & $0.16 \dagger$ & $0.21^{*}$ & - & & & & & 116 \\
\hline (6) Maternal juvenile antisocial symptoms & $0.44^{* *}$ & $0.19^{*}$ & 0.09 & $0.27^{* *}$ & 0.01 & - & & & & 115 \\
\hline (7) Maternal history of psychiatric problems & $0.15 \dagger$ & 0.05 & 0.08 & 0.07 & 0.14 & 0.13 & - & & & 125 \\
\hline (8) Maternal depression from birth to 16 & $0.19^{* *}$ & $0.24^{* *}$ & 0.11 & $0.27^{* *}$ & $0.27^{* *}$ & $0.29^{* *}$ & $0.29^{* *}$ & - & & 108 \\
\hline (9) Family stability & $0.20^{* *}$ & 0.08 & $0.20^{*}$ & 0.12 & $0.16 \dagger$ & 0.09 & 0.06 & 0.14 & - & 111 \\
\hline
\end{tabular}

$\dagger p<0.10$ (trend), ${ }^{*} p<0.05,{ }^{* *} p<0.01$.

standard errors (MLR) was used to calculate estimates. Individual model fit was determined through the $\chi^{2}$ test (acceptable fit $>0.05$ ), which is a suitable fit index for smaller sample sizes (Hayduk et al. 2007; Kline, 2011).

\section{Results}

\section{Maternal childhood maltreatment, offspring exposure to childhood maltreatment and offspring adolescent psychopathology}

Twenty-two (17.6\%) mothers met criteria for classification as having been maltreated as a child. In terms of offspring exposure to childhood maltreatment, 22 $(19.3 \%)$ offspring reported at least one incident of sexual abuse, physical abuse or harsh discipline at 11 years; the mean number of reports of maltreatment was 0.29 (s.D. $=0.63$ ). In terms of offspring psychopathology, at 11 years, $73(65.8 \%)$ children exhibited DBD symptoms and $45(39.5 \%)$ children showed symptoms of depression. At 16 years, 71 (70.3\%) adolescents had DBD symptoms and 72 (67.9\%) adolescents had symptoms of depression. Table 2 shows the intercorrelations between 11- and 16-year DSM-IV symptoms.

Table 3 summarizes the correlations between the study variables, including potential confounders. Maternal childhood maltreatment was associated with offspring exposure to childhood maltreatment (as indicated by a positive correlation; point-biserial coefficient $=0.28, p<0.001$ ). This provided support for our first hypothesis of an association between a mother's experience of maltreatment in her own childhood and her offspring's exposure to maltreatment. When further testing our first hypothesis, with regard to the association between maternal childhood maltreatment and offspring adolescent psychopathology, offspring of maltreated mothers exhibited significantly greater antisocial behaviour in adolescence (pointbiserial coefficient $=0.31, p=0.001$ ) but showed no differences in their levels of depression compared with offspring of mothers not so exposed (point-biserial coefficient $<0.01, p>0.99$ ). Therefore, we were only able to confirm this hypothesis for offspring adolescent antisocial behaviour. We found no effect of offspring gender, offspring ethnicity, maternal education or maternal age at the index pregnancy, on 


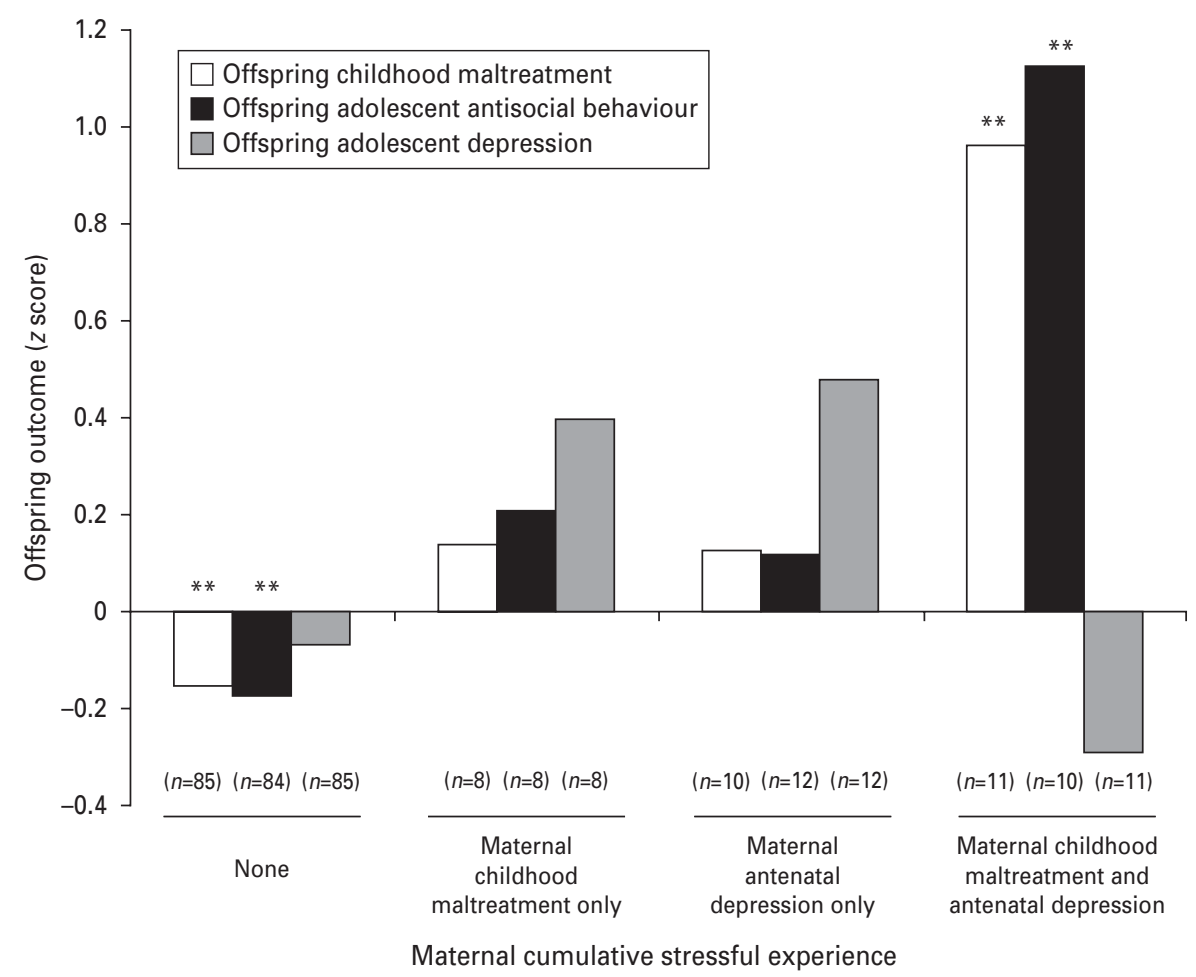

Fig. 1. Mean ( $z$ score) offspring exposure to childhood maltreatment, adolescent antisocial behaviour and adolescent depression as a function of maternal cumulative stressful experience $(* * p<0.01)$.

either maternal or offspring maltreatment or psychopathology.

\section{Maternal childhood maltreatment and maternal antenatal depression}

Twenty-six (20.8\%) mothers met criteria for a clinical diagnosis of depression at 36 weeks of pregnancy. Of the 103 non-maltreated mothers, $12.6 \%(n=13)$ were depressed during pregnancy. By contrast, of the mothers who experienced childhood maltreatment $(n=22)$, a significantly greater proportion $(59.1 \%$, $n=13)$ were depressed antenatally $\left[\chi^{2}(1)=23.76\right.$, $p<0.001$, odds ratio (OR) $10.00,95 \%$ confidence interval (CI) 3.57-28.01]. Logistic regressions revealed that, when entered at the first step, mothers' experiences of childhood maltreatment significantly predicted their antenatal depression $(b=2.30$, Wald statistic $=19.21$, $\mathrm{df}=1, p<0.001)$. This finding remained unchanged when controlling for mothers' own juvenile antisocial symptoms $($ mean $=1.39$, S.D. $=1.73)$, their history of psychiatric problems (26.4\% with a history) and their relationship status during pregnancy ( $4.8 \%$ single), none of which contributed significantly to the explained variance when in the presence of maternal childhood maltreatment. Therefore, maternal experience of childhood maltreatment was the single most powerful predictor of the later occurrence of clinical depression during pregnancy.

\section{Relative impact of maternal childhood maltreatment and antenatal depression}

To test our third hypothesis, we first tested whether offspring outcome varied as a function of maternal cumulative stressful experience. Rates of offspring exposure to childhood maltreatment and adolescent psychopathology were compared across the four levels of maternal cumulative stressful experience (none; maternal childhood maltreatment only; maternal antenatal depression only; maternal childhood maltreatment and maternal antenatal depression). Figure 1 presents the group means as $z$ scores, and demonstrates a double-insult effect of maternal experience of childhood maltreatment and maternal depression during pregnancy, on offspring childhood maltreatment and adolescent antisocial behaviour.

ANOVAs revealed that offspring exposure to childhood maltreatment $\left(n=114, F_{3,110}=4.56, p=\right.$ $0.005)$ and offspring adolescent antisocial behaviour $\left(n=114, F_{3,110}=5.90, p=0.001\right)$ varied in relation to maternal experience of stress. There were no significant group differences for offspring adolescent depression $\quad\left(n=116, \quad F_{3,112}=1.81, \quad p=0.15\right)$. Post-hoc 


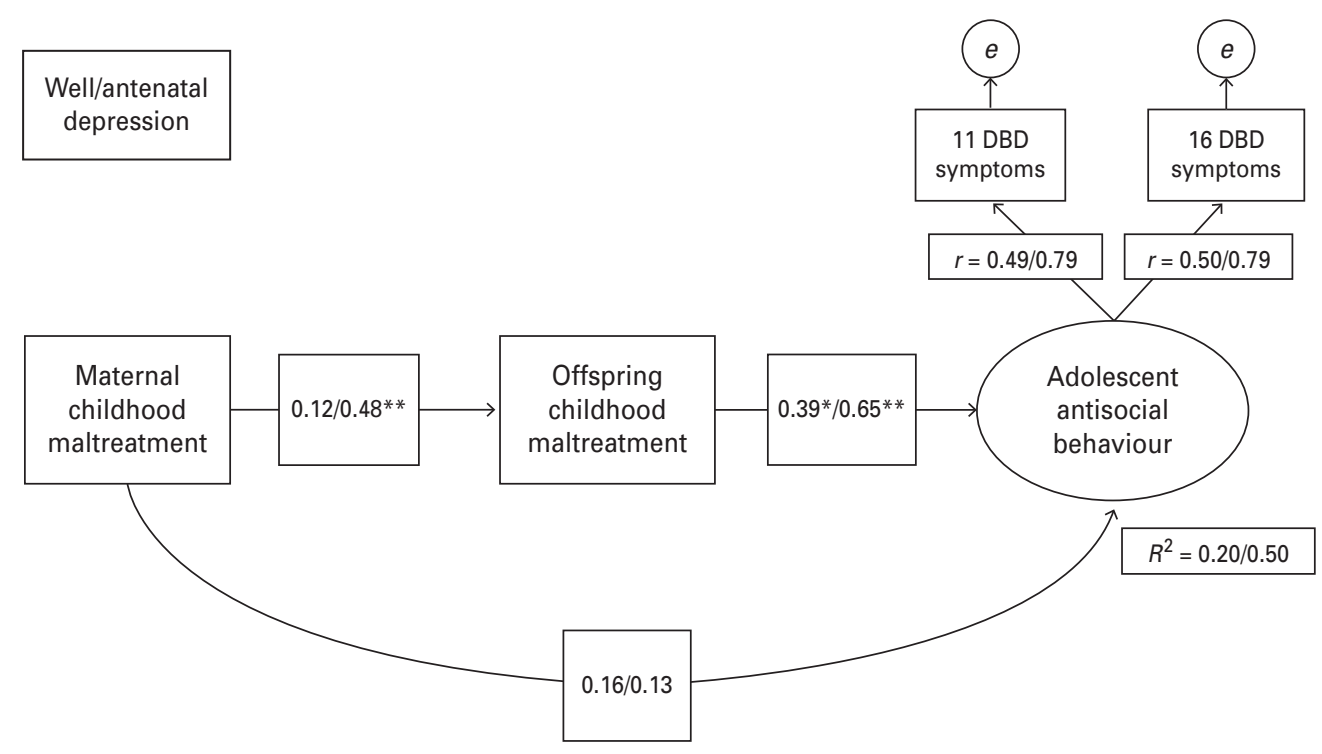

Fig. 2. Path estimates for maternal childhood maltreatment and offspring childhood maltreatment as predictors of adolescent antisocial behaviour. Estimates for offspring not exposed to depression in utero and for those exposed to depression in utero are presented independently. Regression path coefficients are marked as significant at the ${ }^{*} p<0.05$ and ${ }^{* *} p<0.01$ levels. $R^{2}$ for offspring not exposed to depression in utero $=0.20 ; R^{2}$ for offspring exposed to depression in utero $=0.50$. DBD, Disruptive behaviour disorder.

analyses revealed that offspring of mothers who experienced both insults (maternal childhood maltreatment and antenatal depression) exhibited significantly greater levels of childhood maltreatment $(p=0.002)$ and adolescent antisocial behaviour $(p<0.001)$ in comparison to offspring of mothers who experienced neither stress. Offspring whose mothers experienced only one stressful experience did not differ statistically from offspring whose mothers experienced neither stress.

\section{Sequential analysis: pathways from maternal childhood maltreatment to offspring antisocial behaviour}

To evaluate further our third hypothesis, that maternal antenatal depression influences the effect of maternal stress on offspring outcome, we tested a path analytic model that predicted offspring adolescent antisocial behaviour (as this was found to be associated with maternal childhood maltreatment in our preceding analyses). Maternal childhood maltreatment was entered as the predictor, offspring exposure to childhood maltreatment as the mediator and maternal depression during pregnancy as the parameter estimate (well versus antenatal depression). Fig. 2 depicts the path analytic model with path coefficients. We controlled for maternal juvenile antisocial symptoms, maternal previous psychiatric history, maternal depression from birth to 16 , family stability and several maternal and offspring sociodemographic variables (maternal age at birth, maternal education, offspring gender, offspring ethnicity). There was an adequate model fit $\left[\chi^{2}(7)=10.72, p=0.15\right]$. Standardized factor loadings for adolescent antisocial behaviour with DBD symptoms at 11 and 16 years were satisfactory [well mothers, $r=0.49$ (11 years), $r=0.50$ (16 years); antenatal depression, $r=0.79$ (11 years), $r=0.79$ (16 years)].

As shown in Fig. 2, the pathway from mothers' experiences of childhood maltreatment to their offspring's adolescent antisocial behaviour was mediated by their offspring's exposure to childhood maltreatment. Offspring exposure to childhood maltreatment predicted later antisocial behaviour for both the offspring of mothers who were depressed during pregnancy (regression coefficient estimate $=$ $0.65, p=0.001$ ) and for those whose mothers were well during pregnancy (regression coefficient estimate $=0.39, p=0.02$ ). When offspring exposure to childhood maltreatment was taken into account, there was no direct pathway between mothers' childhood maltreatment and their offspring's adolescent antisocial behaviour for either the offspring exposed to depression in utero (regression coefficient estimate $=$ $0.13, p=0.54$ ) or for those not so exposed (regression coefficient estimate $=0.16, p=0.26$ ). Notably, maternal childhood maltreatment significantly predicted offspring exposure to childhood maltreatment in only those offspring exposed to depression in utero 
(regression coefficient estimate $=0.48, p=0.004$ ), and this pathway was not significant for offspring of mothers who were well during pregnancy (regression coefficient estimate $=0.12, p=0.48$; differences between these estimates, however, were at the trend level). The overall model accounted for $50 \%$ of the variance in offspring's levels of adolescent antisocial behaviour for those who were exposed to depression in utero. In summary, antenatal depression moderated the effect of maternal childhood maltreatment, whereby it is the co-occurrence of maternal childhood maltreatment and antenatal depression that provides a pathway for the intergenerational transmission of maternal stress effects. This supports the findings presented in Fig. 1 on the effects of maternal cumulative stressful experience.

\section{Discussion}

The present study used a longitudinal design to investigate the relative impact of maternal experience of childhood maltreatment and maternal antenatal depression on offspring exposure to maltreatment and psychopathology. We demonstrate, for the first time, an association between maternal experience of childhood maltreatment and maternal antenatal depression. Moreover, we find that maternal cumulative stress, that is the co-occurrence of maternal childhood maltreatment and maternal antenatal depression, significantly increases offspring childhood maltreatment and adolescent antisocial behaviour.

\section{Maternal childhood maltreatment and offspring exposure to childhood maltreatment and psychopathology}

Our data reveal an association between a mother's childhood maltreatment and her offspring's exposure to maltreatment in the period from birth to 11 years. This finding complements and extends those of Berlin et al. (2011) and Sidebotham \& Heron (2006), who have demonstrated a link between maternal childhood maltreatment and offspring childhood maltreatment in early childhood. In terms of offspring psychopathology, our data indicate an association between maternal childhood maltreatment and offspring adolescent antisocial behaviour. We did not, however, find an association with offspring adolescent depression. Levels of depression tend to increase through the transition period from childhood into adolescence and then young adulthood (Costello et al. 2011) and, furthermore, depression in adolescence is commonly preceded by DBDs (Hipwell et al. 2011). Our data seem to reflect these observations because we demonstrate significant associations between DBD symptoms at 11 and depression symptoms at 16 (see Table 2). An implication of these findings is that, to detail a true picture of offspring depression, the later adolescent years and young adulthood years may provide the optimum period in which to investigate its prevalence, rather than early adolescence. It is therefore plausible to speculate than an association between maternal childhood maltreatment and offspring depression may become apparent when offspring reach adulthood.

\section{Maternal childhood maltreatment and maternal antenatal depression}

The association between a woman's experience of maltreatment in her childhood and the onset of clinically diagnosed depression during pregnancy is a novel finding. Our data indicate this to be a robust relationship that remains true even when accounting for a woman's antisocial characteristics, her personal history of psychiatric illness outside pregnancy and the availability of partner support during pregnancy, all of which have been identified as salient factors that are associated with maternal psychopathology (KimCohen et al. 2006; Bifulco et al. 2009; Bowen et al. 2009; Hay et al. 2010). A history of childhood maltreatment thus seems to be a prominent indicator of whether a woman will experience clinical depression specifically during pregnancy. This finding is consistent with many epidemiological and clinical studies linking depressive symptomatology in the antenatal period to maternal experiences of childhood maltreatment (Romano et al. 2006; Chung et al. 2008; Rich-Edwards et al. 2011), but is demonstrated here for the first time for clinically diagnosed antenatal depression.

In addition to the possible psychological and psychosocial processes that may underpin the pathway from childhood maltreatment to adulthood depression, such as the role of shame and low selfesteem (Brown et al. 2008), research into biological mechanisms can offer promising insights into some of the likely pathophysiological processes that are particularly relevant to the increased risk during pregnancy. For example, childhood maltreatment has been shown to predispose to hyperactivity of the hypothalamic-pituitary-adrenal (HPA) axis and also to increased inflammation, both of which are considered part of the pathogenesis of depression (Heim et al. 2001; Pace et al. 2006; Danese et al. 2007, 2008). It is therefore plausible to speculate that women who suffer childhood maltreatment carry biological abnormalities that predispose them to develop depression in pregnancy, which is itself associated with increased HPA axis activity and inflammation (Coussons-Read et al. 2007; O'Keane et al. 2011). 


\section{Mechanisms underlying the intergenerational transmission of childhood maltreatment and psychopathology}

We find that it is the impact of maternal cumulative stress, that is the co-occurrence of a mother's experience of childhood maltreatment and depression during pregnancy, that significantly increases offspring childhood maltreatment and antisocial behaviour. These two maternal characteristics are highly associated, and we find that it is their concerted effect that significantly contributes to offspring adversity. Thus, we propose that a woman's experience of childhood maltreatment increases the risk of her developing depression in pregnancy, which in turn confers further risk for her offspring, and this provides a vehicle for the intergenerational transmission of risk for maltreatment and psychopathology. We formally tested this argument through a path analytic model starting from a mother's childhood maltreatment to her offspring's antisocial behaviour during adolescence, in which we assessed the relative contributions of depression during pregnancy and her offspring's exposure to childhood maltreatment. We find, first, that the pathway from a mother's experience of childhood maltreatment to her offspring's adolescent antisocial behaviour is mediated by her offspring's exposure to childhood maltreatment; and, second, that the effect of a mother's experience of childhood maltreatment on her offspring's likelihood of being exposed to childhood maltreatment is moderated by her antenatal depression.

Two main conclusions can be drawn from these findings. First, women at risk for developing depression during their pregnancy could be identified through a brief childhood social history, and antenatal depression could be targeted therapeutically as a preventative strategy to break the intergenerational transmission of adversity. Second, offspring exposure to childhood maltreatment plays a mediating role in the link between a mother's psychosocial adversity and her offspring's antisocial behaviour. This latter finding is consistent with those of Harold et al. (2011) and Bornovalova et al. (2010), who have demonstrated the notable role of environmentally mediated effects (in our study, childhood exposure to maltreatment) in the development of antisocial behaviour problems.

Our data also complement the wealth of preclinical and clinical studies that propose that the hormonal environment afforded by the mother during pregnancy can programme persistent foetal brain changes that confer risk to the offspring for maladjustment in later life (Seckl \& Holmes, 2007; Talge et al. 2007; Beydoun \& Saftlas, 2008). However, the specific mechanisms underlying this intergenerational pathway are as yet unknown. Non-mutually exclusive mechanisms could include the putative effects of antenatal depression on attachment (Misri \& Kendrick, 2008), offspring temperament and disruptions to maternal care, including a mother's ability to protect her young. It is important to highlight that our results do not suggest that all mothers who have experienced such insults will go on to expose their children to maltreatment: indeed, most do not. Moreover, in our original description of the association between maternal antenatal depression and offspring maltreatment, we have shown that, of the children who were exposed to maltreatment, in $52 \%$ of these cases mothers were not the perpetrators of the maltreatment (Pawlby et al. 2011). Rather, our interpretation is that mothers who experience these insults may be less able to protect their children from other perpetrators.

\section{Limitations and directions for future research}

Alongside the numerous strengths of our investigation, such as the use of a prospective design starting in pregnancy through 17 years to chart offspring development, and the collection of data through corroborative parent and child reports from one-to-one interviews conducted at various offspring ages, there are some limitations that need to be highlighted. First, our measure of maternal childhood maltreatment is retrospective, which introduces the risk of reporting bias. However, Brown et al. (2007) conducted a validation study in which they demonstrated no significant reporting bias of parental maltreatment collected through semi-structured interview methods in a sample similar to ours. Second, our sample is small and limited to a city population of women who were pregnant more than 20 years ago. It is therefore difficult to generalize these findings to other socioeconomic groups or more recent cohorts. An additional consequence of our small sample size is that few mothers and offspring presented with childhood maltreatment and psychopathology. Thus, we were unable to analyse within-group differences on factors such as maltreatment type or who the perpetrator was.

In terms of future research, the overall implications of our study support the view that maternal childhood maltreatment and maternal antenatal depression are indeed common elements to a single intergenerational pathway of the transmission of maternal stress effects. From a clinical standpoint, the antenatal period presents a unique opportunity to identify and offer support to women who may be vulnerable to developing depression during their pregnancy. At-risk women could be identified by a few simple questions about the quality of their upbringing, and assertive treatment of antenatal depression might be a clear 
therapeutic strategy to break the intergenerational transmission of childhood maltreatment and psychopathology.

\section{Supplementary material}

For supplementary material accompanying this paper visit http:/ /dx.doi.org/10.1017/S0033291712001298.

\section{Acknowledgements}

This study was supported by Medical Research Council UK project grants G89292999N and G9539876N, a grant from the Psychiatry Research Trust (McGregor 97) awarded to S.P., and the South West General Practitioner Trust. D.T.P. is funded by a grant from the Psychiatry Research Trust (McGregor 97), Institute of Psychiatry, King's College London, UK. E.D.B. is employed by Birkbeck, University of London, UK. C.S.W. is employed by Cardiff and Vale University Health Board, Cardiff, UK. S.P. is funded by the South London and Maudsley National Health Service (NHS) Foundation Trust and Institute of Psychiatry, King's College London, UK. C.M.P. is funded by the National Institute for Health Research (NIHR) Mental Health Biomedical Research Centre at South London and Maudsley NHS Foundation Trust and King's College London, UK.

We thank H. Allen, A. Mills and G. Schmücker for their assistance with data collection, and we are especially grateful to the families of the South London Child Development Study who continue to give so generously of their time.

\section{Declaration of Interest}

None.

\section{References}

Angold A, Costello EJ (2000). The Child and Adolescent Psychiatric Assessment (CAPA). Journal of the American Academy of Child and Adolescent Psychiatry 39, 39-48.

Berlin LJ, Appleyard K, Dodge KA (2011). Intergenerational continuity in child maltreatment: mediating mechanisms and implications for prevention. Child Development 82, 162-176.

Beydoun H, Saftlas AF (2008). Physical and mental health outcomes of prenatal maternal stress in human and animal studies: a review of recent evidence. Paediatric and Perinatal Epidemiology 22, 438-466.

Bifulco A, Moran P, Jacobs C, Bunn A (2009). Problem partners and parenting: exploring linkages with maternal insecure attachment style and adolescent offspring internalizing disorder. Attachment and Human Development 11, 69-85.
Bifulco A, Moran PM, Baines R, Bunn A, Stanford K (2002). Exploring psychological abuse in childhood: II. Association with other abuse and adult clinical depression. Bulletin of the Menninger Clinic 66, 241-258.

Bornovalova MA, Hicks BM, Iacono WG, McGue M (2010). Familial transmission and heritability of childhood disruptive disorders. American Journal of Psychiatry 167, 1066-1074.

Bowen A, Stewart N, Baetz M, Muhajarine N (2009). Antenatal depression in socially high-risk women in Canada. Journal of Epidemiology and Community Health 63, 414-416.

Brown GW, Craig TK, Harris TO (2008). Parental maltreatment and proximal risk factors using the Childhood Experience of Care \& Abuse (CECA) instrument: a life-course study of adult chronic depression - 5. Journal of Affective Disorders 110, 222-233.

Brown GW, Craig TK, Harris TO, Handley RV, Harvey AL (2007). Validity of retrospective measures of early maltreatment and depressive episodes using the Childhood Experience of Care and Abuse (CECA) instrument - a life-course study of adult chronic depression - 2. Journal of Affective Disorders 103, 217-224.

Chung EK, Mathew L, Elo IT, Coyne JC, Culhane JF (2008). Depressive symptoms in disadvantaged women receiving prenatal care: the influence of adverse and positive childhood experiences. Ambulatory Pediatrics 8, 109-116.

Collishaw S, Dunn J, O'Connor TG, Golding J (2007). Maternal childhood abuse and offspring adjustment over time. Development and Psychopathology 19, 367-383.

Costello EJ, Copeland W, Angold A (2011). Trends in psychopathology across the adolescent years: what changes when children become adolescents, and when adolescents become adults? Journal of Child Psychology and Psychiatry 52, 1015-1025.

Coussons-Read ME, Okun ML, Nettles CD (2007). Psychosocial stress increases inflammatory markers and alters cytokine production across pregnancy. Brain, Behavior and Immunity 21, 343-350.

Danese A, Moffitt TE, Pariante CM, Ambler A, Poulton R, Caspi A (2008). Elevated inflammation levels in depressed adults with a history of childhood maltreatment. Archives of General Psychiatry 65, 409-415.

Danese A, Pariante CM, Caspi A, Taylor A, Poulton R (2007). Childhood maltreatment predicts adult inflammation in a life-course study. Proceedings of the National Academy of Sciences USA 104, 1319-1324.

Edwards VJ, Holden GW, Felitti VJ, Anda RF (2003). Relationship between multiple forms of childhood maltreatment and adult mental health in community respondents: results from the adverse childhood experiences study. American Journal of Psychiatry 160, 1453-1460.

Endicott J, Spitzer RL (1978). A diagnostic interview : the schedule for affective disorders and schizophrenia. Archives of General Psychiatry 35, 837-844.

Goldberg D, Cooper B, Eastwood MT, Kedward HB, Shepherd M (1970). A standardised psychiatric interview 
for use in community surveys. British Journal of Preventive and Social Medicine 24, 18-23.

Goldthorpe JH, Hope K (1974). The Social Grading of Occupations: A New Approach and Scale. Clarendon Press: Oxford.

Harold GT, Rice F, Hay DF, Boivin J, van den Bree M, Thapar A (2011). Familial transmission of depression and antisocial behavior symptoms: disentangling the contribution of inherited and environmental factors and testing the mediating role of parenting. Psychological Medicine 41, 1175-1185.

Hay DF, Pawlby S, Waters CS, Perra O, Sharp D (2010). Mothers' antenatal depression and their children's antisocial outcomes. Child Development 81, 149-165.

Hayduk L, Cummings GG, Boadu K, Pazderka-Robinson H, Boulianne S (2007). Testing! testing! one, two three - Testing the theory in structural equation models! Personality and Individual Differences 42, 841-850.

Heim C, Newport DJ, Bonsall R, Miller AH, Nemeroff CB (2001). Altered pituitary-adrenal axis responses to provocative challenge tests in adult survivors of childhood abuse. American Journal of Psychiatry 158, 575-581.

Hipwell AE, Stepp S, Feng X, Burke J, Battista DR, Loeber R, Keenan K (2011). Impact of oppositional defiant disorder dimensions on the temporal ordering of conduct problems and depression across childhood and adolescence in girls. Journal of Child Psychology and Psychiatry 52, 1099-1108.

Kim-Cohen J, Caspi A, Rutter M, Tomas MP, Moffitt TE (2006). The caregiving environments provided to children by depressed mothers with or without an antisocial history. American Journal of Psychiatry 163, 1009-1018.

Kline RB (2011). Principles and Practice of Structural Equation Modeling. Guilford Press: New York.

Maughan B, Taylor A, Caspi A, Moffitt TE (2004). Prenatal smoking and early childhood conduct problems: testing genetic and environmental explanations of the association. Archives of General Psychiatry 61, 836-843.

Miranda JK, de la Osa N, Granero R, Ezpeleta L (2011). Maternal experiences of childhood abuse and intimate partner violence: psychopathology and functional impairment in clinical children and adolescents. Child Abuse and Neglect 35, 700-711.

Misri S, Kendrick K (2008). Perinatal depression, fetal bonding, and mother-child attachment: a review of the literature. Current Pediatric Reviews 4, 66-70.

Muthén LK, Muthén BO (1998-2010). Mplus User's Guide. Muthén \& Muthén: Los Angeles, CA.

Nanni V, Uher R, Danese A (2012). Childhood maltreatment predicts unfavorable course of illness and treatment outcome in depression: a meta-analysis. American Journal of Psychiatry 169, 141-151.

O'Keane V, Lightman S, Marsh M, Pawlby S, Papadopoulos AS, Taylor A, Moore R, Patrick K (2011). Increased pituitary-adrenal activation and shortened gestation in a sample of depressed pregnant women: a pilot study. Journal of Affective Disorders 130, 300-305.

Pace TW, Mletzko TC, Alagbe O, Musselman DL, Nemeroff CB, Miller AH, Heim CM (2006). Increased stress-induced inflammatory responses in male patients with major depression and increased early life stress. American Journal of Psychiatry 163, 1630-1633.

Pawlby S, Hay D, Sharp D, Waters CS, Pariante CM (2011). Antenatal depression and offspring psychopathology: the influence of childhood maltreatment. British Journal of Psychiatry 199, 106-112.

Pawlby S, Hay DF, Sharp D, Waters CS, O'Keane V (2009). Antenatal depression predicts depression in adolescent offspring: prospective longitudinal community-based study. Journal of Affective Disorders 113, 236-243.

Rice F, Harold GT, Boivin J, van den Bree M, Hay DF, Thapar A (2010). The links between prenatal stress and offspring development and psychopathology: disentangling environmental and inherited influences. Psychological Medicine 40, 335-345.

Rich-Edwards JW, James-Todd T, Mohllajee A, Kleinman K, Burke A, Gillman MW, Wright RJ (2011). Lifetime maternal experiences of abuse and risk of pre-natal depression in two demographically distinct populations in boston. International Journal of Epidemiology 40, 375-384.

Romano E, Zoccolillo M, Paquette D (2006). Histories of child maltreatment and psychiatric disorder in pregnant adolescents. Journal of the American Academy of Child and Adolescent Psychiatry 45, 329-336.

Rutter M (2006). Genes and Behavior: Nature-Nurture Interplay Explained. Blackwell: Oxford.

Seckl JR, Holmes MC (2007). Mechanisms of disease: glucocorticoids, their placental metabolism and fetal 'programming' of adult pathophysiology. Nature Clinical Practice Endocrinology and Metabolism 3, 479-488.

Sharp D, Hay DF, Pawlby S, Schmücker G, Allen H, Kumar R (1995). The impact of postnatal depression on boys' intellectual development. Journal of Child Psychology and Psychiatry 36, 1315-1336.

Sidebotham P, Heron J (2006). Child maltreatment in the 'children of the nineties' : a cohort study of risk factors. Child Abuse and Neglect 30, 497-522.

Talge NM, Neal C, Glover V (2007). Antenatal maternal stress and long-term effects on child neurodevelopment: how and why? Journal of Child Psychology and Psychiatry 48, 245-261.

Thapar A, Rutter M (2009). Do prenatal risk factors cause psychiatric disorder? Be wary of causal claims. British Journal of Psychiatry 195, 100-101.

Widom CS, DuMont K, Czaja SJ (2007). A prospective investigation of major depressive disorder and comorbidity in abused and neglected children grown up. Archives of General Psychiatry 64, 49-56. 